\title{
The Human Genetics of Dental Anomalies
}

\author{
${ }^{1}$ Department of Orthodontics \& Dentofacial Orthopedics, The Oxford \\ Dental College, Bangalore, Karnataka, India \\ 2 General Dental Practitioner, Max Dental Specialties, Bangalore, \\ Karnataka, India \\ ${ }^{3}$ Department of Orthodontics \& Dentofacial Orthopedics, Kamineni \\ Institute of Dental Sciences, Narketpally, Andhra Pradesh, India \\ ${ }^{4}$ General Dental Practitioner, The Dental Clinic, Bangalore, Karnataka, \\ India
}

Mahamad Irfanulla Khan ${ }^{1}$ Nadeem Ahmed ${ }^{2}$ Praveen Kumar Neela ${ }^{3}$ Nayeem Unnisa ${ }^{4}$

Address for correspondence Mahamad Irfanulla Khan, BDS, MDS, Department of Orthodontics \& Dentofacial Orthopedics, The Oxford Dental College, Bangalore 560068, Karnataka, India (e-mail: drirfankhanmds@gmail.com).

Glob Med Genet 2022;9:76-81.

\author{
Abstract \\ Keywords \\ - tooth development \\ - dental anomalies \\ - genetics \\ - genes \\ - mutations
}

The development of tooth is a highly complex procedure and mastered by specific genetic programs. Genetic alterations, environmental factors, and developmental timing can disturb the execution of these programs, and result in various dental anomalies like hypodontia/oligodontia, and supernumerary teeth, which are commonly seen in our clinical practice. Advances in molecular research enabled the identification of various genes involved in the pathogenesis of dental anomalies. In the near future, it will help provide a more accurate diagnosis and biological-based treatment for these anomalies. In this article, we present the molecular phenomenon of tooth development and the genetics of various dental anomalies.

\section{Introduction}

The tooth is a specialized organ of the maxillofacial skeleton and its development involves a series of lengthy and complex stages. ${ }^{1}$ Tooth development is influenced by genetic and environmental factors. ${ }^{2}$ Tooth number, position, structure, and shape are under the control of a complex system of certain genes whose modifications may result in dental anomalies. ${ }^{3}$ Depending on the stage of tooth development where alteration takes place, different dental anomalies could occur in terms of number (anodontia, hypodontia, and hyperdontia), structure (amelogenesis imperfecta [AI], dentinogenesis imperfect, and dentin dysplasia), and shape (microdontia, macrodontia, and taurodontism). ${ }^{4}$ These anomalies may be associated with the systemic disorder (syndromic) or isolated (nonsyndromic). Dental anomalies may create problems of aesthetics as well as speech, which requires a multidisciplinary approach for the treatment of these anomalies. 5

Advances in molecular genetics enabled us to identify the various genes involved in the pathogenesis of dental anoma-

received

November 24, 2021

accepted

December 29, 2021 lies. This article describes the molecular phenomenon of tooth development and the genetics of various dental anomalies.

\section{Tooth Development and Genetic Basis of Dental Anomalies}

In humans, the development of teeth involves several distinctive cellular and molecular interaction processes. The deciduous and permanent teeth develop from the oral ectoderm and the underlying neural mesenchymal cells, which have migrated from the cranial neural crest to the facial process. ${ }^{7}$ During the 6 th week of human development, a line of oral epithelium cells condenses to form the dental lamina, which develops several tooth buds, invading the underlying mesenchyme. These reciprocal interactions of epithelial cells and mesenchymal tissues modulate tooth development. ${ }^{8}$ The center of the epithelial mass known as the enamel knot functions as an important signaling center for the regulation of tooth shape. ${ }^{9}$

\section{(C) 2022. The Author(s).}

This is an open access article published by Thieme under the terms of the Creative Commons Attribution License, permitting unrestricted use, distribution, and reproduction so long as the original work is properly cited. (https://creativecommons.org/licenses/by/4.0/) Georg Thieme Verlag KG, Rüdigerstraße 14, 70469 Stuttgart, Germany 
The earliest stages of human embryogenesis involve the formation of the head for which a specific group of cells with stem cell properties called cranial neural crest cells (CNCs) are of importance. Except for muscles that are formed by mesodermal cells, the CNC is responsible for the development of the entire head structures. ${ }^{10}$ The CNC further specifies and is organized into particular elements like bones and teeth by way of a unique continuous "molecular dialogue" or interaction with the epithelium that covers the developing face and oral cavity. ${ }^{11}$ The interaction of CNC with epithelium through this molecular dialogue involves certain proteins that are products of specific genes. These proteins command cells to either divide or die (apoptosis), migrate/proliferate, or differentiate into more distinct cell types such as osteoblasts, odontoblasts, and chondrocytes. ${ }^{12,13}$

Orofacial and dental disorders occur as a result of mutations in the sequence of either a gene or a group of genes because of alterations to the expression or function of the encoded protein(s). ${ }^{14}$ Apart from genetic mutations, environmental factors can affect the expression of genes or interfere with the normal function of their protein products. ${ }^{15}$ The position, number, and shapes of different types of teeth are determined by more than 300 genes. ${ }^{16}$ The homeobox (HOX) genes are the most commonly studied genes in relation to tooth development, and they are expressed in the migrating neural crest cells. Between 18 and 24 weeks of development, the HOX gene network appears to be active in human tooth germs. ${ }^{17}$ The PAX, MSX, DLX, LHX, BARX, and RUNX2 are the key members of the HOX genes engaged in the development of the tooth. ${ }^{18}$

The BMP (bone morphogenetic protein), FGF (fibroblast growth factor), TGFb (transforming growth factor b), EGF (epidermal growth factor), SHH (sonic hedgehog), and the WNT (wingless) families are the major signaling molecules involved in the regulation of tooth embryogenesis. ${ }^{19,20}$ The Msx-2 gene expression was localized to enamel knot cells, and its expression during tooth development provided a molecular link between tooth initiation and shape. ${ }^{21}$ Literature database has shown that the mutations in many of these genes cause dental anomalies in mice as well as in humans. ${ }^{22,23}$

\section{Genes Involved In Dental Anomalies}

\section{Tooth Number Anomalies}

Tooth number anomalies are characterized by either the presence in excess or absence of teeth than the usual number of primary or permanent dentitions due to changes in the dental lamina or tooth germ during tooth development. ${ }^{24}$

\section{Tooth Agenesis}

Tooth agenesis (OMIM \# 106600) refers to the congenital absence of teeth and occurs as a consequence of disturbances in their initial tooth development stages of tooth formation and proliferation. Its prevalence is between 1.6 and $9.6 \%$ and is seen more in females than in males. The most common teeth that show tooth agenesis are the third molars (9-30\%), followed by mandibular second premolars (3-4\%) and then maxillary lateral incisors (2.2\%) and maxillary second premolars. Except for maxillary lateral incisors, unilateral agenesis is more frequent than bilateral agenesis. ${ }^{25}$

The etiology of tooth agenesis is multifactorial, which includes genetic, epigenetic, and environmental factors. ${ }^{26}$ It may occur as an isolated (nonsyndromic) or as a part of syndromes (syndromic). Several environmental factors like irradiation, chemotherapeutic agents, and dioxin can arrest tooth development. But the genetic factor supersedes the environmental factor in causing tooth agenesis, which is supported by molecular studies of familial autosomal dominant tooth agenesis associated with mutations in genes expressed in early tooth development such as paired box 9 (PAX9), muscle segment homeobox 1 (MSX1), axis inhibitor 2 (AXIN2), and ectodysplasin A (EDA). Tooth agenesis occurs more frequently in monozygotic twins and it indicates a notable influence of genetic factors. ${ }^{27,28}$

A literature search determined the most important candidate genes whose mutations are responsible for tooth agenesis include MSX1, PAX9, EDA, ectodysplasin A receptor (EDAR), AXIN2, and Wingless type 10A (WNT10A) genes. The genes involved in the development of various dental anomalies are presented in -Table $\mathbf{1}$.

\section{Nonsyndromic Tooth Agenesis}

Isolated, nonsyndromic tooth agenesis can present as sporadic or familial and may be inherited as an autosomal

Table 1 Genes involved in the development of dental anomalies in humans

\begin{tabular}{|c|c|c|c|c|}
\hline SI. no. & Dental anomaly & OMIM & Gene(s) & Studies \\
\hline 1 & Tooth agenesis & 106600 & $\begin{array}{l}\text { MSX1, PAX9, AXIN2, } \\
\text { WNT10A, and EDA }\end{array}$ & $\begin{array}{l}\text { Gerits et al, }{ }^{27} \text { Lidral and Reising, }{ }^{29} \\
\text { Stockton et al, }{ }^{32} \text { Lammi et al, }{ }^{39} \\
\text { Kantaputra and Sripathomsawat, }{ }^{41} \text { Song et al }{ }^{42}\end{array}$ \\
\hline 2 & Supernumerary teeth & 187100 & $R U N X 2, A P C$ & Cohen, ${ }^{51}$ Inchingolo et al $^{52}$ \\
\hline 3 & Amelogenesis imperfecta & 104530 & $\begin{array}{l}\text { AMELX, ENAM, } \\
\text { MMP20, KLK4, DLX3 }\end{array}$ & $\begin{array}{l}\text { Greene et al, }{ }^{55} \text { Ozdemir et al, } \\
\text { Kim et al, }{ }^{58} \text { Hart et al, }{ }^{59} \text { Dong et al }\end{array}$ \\
\hline 4 & Dentinogenesis imperfecta & 125490 & $D S P P$ & Lee et al, ${ }^{66}$ Zhang et al ${ }^{68}$ \\
\hline 5 & Taurodontism & 272700 & $D L X 3, M M P 2$ & Whitehouse et al, ${ }^{74}$ Andersson et $\mathrm{al}^{75}$ \\
\hline
\end{tabular}


dominant, recessive, or X-linked mode. It may be classified as hypodontia, oligodontia, or anodontia. The absence of one to six teeth excluding the third molars is termed hypodontia, and the absence of more than six teeth excluding the third molars is known as oligodontia (OMIM \#604625). The congenital absence of all teeth is termed anodontia (OMIM \#206780) and is usually associated with syndromes.

\section{Muscle Segment Homeobox 1 (MSX1)}

Human MSX1 gene located at 4p16.1 spans around $4.05 \mathrm{~kb}$ and consists of two exons that encode a homeodomain-a 297 amino acid protein and 1 intron. ${ }^{29}$ It plays a vital role during the development of teeth and craniofacial structures. $^{30}$ Mutations in the MSX1 gene mapped to 4p16.2 showed a second premolar and a third molar hypodontia. ${ }^{31}$

\section{The Paired Box 9 (PAX9)}

PAX9 gene is a member of the paired box (PAX) family and is located at $14 q 13.3$. They encode proteins that share a 128amino acid DNA binding domain and are important regulators of numerous developmental processes. ${ }^{32,33}$ Pax9 plays an important role during tooth development, and high levels of Pax9 expression are maintained throughout the initiation, bud, cap, and bell stages of tooth development. ${ }^{34,35}$ Nieminen et al and Klein et al reported mutations of the PAX9 gene led to nonsyndromic oligodontia of the molar teeth. ${ }^{36,37}$ Several studies indicated an important partnership between the thePax9 paired domain protein and the Msx1 homeoprotein in regulating gene expression in dental mesenchymal tissue. In humans, a heterozygous mutation in either PAX9 or MSX1 causes tooth agenesis of molar and premolar teeth, respectively. ${ }^{38}$

\section{The Axis inhibitor 2 (AXIN2)}

AXIN2 gene is located at 17q24.1 and encodes the Axin2 protein that plays an important role in regulating the stability of $\beta$-catenin, which is involved in the Wnt signaling pathway (wingless). AXIN2 mutations result in hypodontia and oligodontia associated with colorectal cancer. ${ }^{39}$ It was found that the oligodontia caused by the AXIN2 gene was more severe than that described for mutations in MSX1 and PAX9 genes; there were more missing molars, premolars, upper lateral incisors, and lower incisors. ${ }^{40}$

\section{Wingless-type 10A (WNT10A)}

$W N T 10 A$ gene, located at 2q35, contains 4 exons and belongs to the WNT gene family encoding the expression of signaling proteins on the cell surface and is associated with several syndromes (ectodermal dysplasia), but also nonsyndromic hypodontia. $^{41}$

\section{Syndromic Tooth Agenesis}

Mutations in the genes that are involved in tooth development as well as development of other organs result in tooth agenesis, which is associated with many syndromes. Syndromes associated with tooth agenesis are ectodermal dysplasia, Rieger's syndrome, and Witkop's tooth and nail syndrome. ${ }^{42}$ In ectodermal dysplasia, mutations in EDA and gap junction protein
Beta 6 (GJB6) were observed. The MSX1 homeobox gene are responsible for Witkop's tooth and nail syndrome, and Rieger's syndrome is a result of mutations in paired-like homeodomain transcription factor 2 (PITX2) gene, which is involved in tooth development. $^{43}$

Mutations in the EDA gene mapped at Xq13.1 showed an Xlinked hypohidrotic ectodermal dysplasia (HED), a rare disease characterized by hypoplasia or absence of sweat glands, dry skin, sparse hair, and pronounced oligodontia. ${ }^{44,45}$

\section{Supernumerary Teeth}

Supernumerary teeth or hyperdontia (OMIM \#187100) are characterized by an excess in the number of teeth from usual for any given region of the dental arch. They may occur unilaterally or bilaterally, single or in multiples in any region of dental arches. ${ }^{46}$ Both primary and permanent dentitions are affected, but most commonly seen in permanent dentition with the prevalence rate of 0.3 to $3.0 \%$. Patients with supernumerary primary teeth may have 30 to $50 \%$ chances of these being followed by supernumerary permanent teeth. They are more frequently present in males than in females. Premaxilla is the most common site of its occurrence with mesiodense. $^{47,48}$

Different explanations ranging from the dichotomy of tooth germs and hyperactivity of dental lamina to remnants of epithelial cells were proposed, but the etiology remains unclear. Although genetic influences are reported in relation to its occurrence, environmental factors were also responsible. Supernumerary teeth may be transmitted through autosomal dominant or autosomal recessive traits with incomplete penetrance or may be associated with an $\mathrm{X}$ chromosome. In most cases, supernumerary teeth have been reported in patients with syndromes such as cleidocranial dysplasia, Ehlers-Danlos syndrome type III, Ellis-Van Creveld syndrome, Gardner's syndrome, Goldenhar's syndrome, Hallermann-Streiff syndrome, orofaciodigital syndrome type I, Nance-Horan syndrome, and cleft lip and/or palate. $^{49,50}$

Genetic studies found heterozygous mutations of the runt-related transcription factor 2 (RUNX2) gene, which is located at $6 \mathrm{p} 21$, to be responsible for the development of cleidocranial dysplasia. ${ }^{51}$ A mutation in the APC gene located on chromosome $5 q 22.2$ is found to be a causative factor for Gardner's syndrome. It is also proposed that inactivation of APC or forced activation of Wnt/ 3 (catenin signaling) results in multiple supernumerary teeth formation in both humans and mice, but key genes in these pathways are not very clear. $^{52}$

\section{Structural Anomalies}

\section{Amelogenesis Imperfecta}

AI (OMIM \# 104530) refers to a rare, genetically, and clinically heterogeneous group of inherited disorders characterized by abnormal enamel formation qualitatively or quantitatively. It can present as locally deficient enamel as hypoplasia or aplasia, which is complete enamel absence. Clinically a patient with AI shows yellow to brown-colored 
teeth with or without opacities, microdontia to normal size depending on enamel thickness. ${ }^{53}$ The prevalence of $\mathrm{AI}$ ranges from 1 in 700 to 1 in 4,000 in different populations. It may present as autosomal dominant, autosomal recessive, or X linked. Usually, AI is a nonsyndromic enamel defect, but other dental anomalies may be associated with it like pulp calcification, taurodontism, delayed eruption, and gingival overgrowth. The AI phenotype is broadly categorized into hypoplastic, hypomaturation, and hypocalcified. ${ }^{54}$

The etiology is poorly understood and controversial be it a local mechanism, environmental aspect, or genetic mutations. Present literature reports that the amelogenin (AMELX), ${ }^{55}$ enamelin (ENAM), ${ }^{56,57}$ matrix metalloproteinase 20 (MMP20), ${ }^{58}$ and kallikrein 4 (KLK4) $)^{59}$ genes are involved in the development of AI. But it is not clear that all AI causing genes have been identified. The distal-less homeobox 3 (DLX3) gene causes $\mathrm{AI}$ as a part of trichodento-osseous (TDO) syndrome. ${ }^{60}$ If the hair and bone abnormalities in TDO are not noticeable, the condition is designated AI hypoplastic hypomaturation with taurodontism (AIHHT). ${ }^{61,62}$

\section{Dentinogenesis Imperfecta}

Dentinogenesis imperfecta (DI; OMIM \# 125490) is a hereditary developmental defect of dentin formation that results in the appearance of opalescent teeth. The teeth usually appear blue-gray or yellow brown in color. ${ }^{63}$ It is generally inherited in simple autosomal dominant mode with high penetrance and low mutation rates. Both the primary and permanent dentition is affected by DI. The overlying enamel is normal in structure but breaks easily due to poor dentin exposing it to the oral environment, which results in weaker teeth prone to recurrent bacterial infections. ${ }^{64,65}$

Although the classification provided by Witkop and Shields are well accepted, they are not satisfactory. Genetic studies on DI type 1 have confirmed that osteogenesis imperfecta is a separate entity from DI and only a single genetic mutation of the dentin sialophosphoprotein (DSPP) gene located at chromosome 4 q21.3 is responsible for causing DI type 2 and DI type $3 .^{66,67}$ The gene product is a precursor protein that is halved into two dentin-specific proteins: dentin sialoprotein (DSP) and dentin phosphoprotein (DPP). The genetic basis for this heterogeneity is not known. Osteogenesis imperfecta results from mutations in gene encoding type 1 collagens-collagen 1A1 (COL1A1) and collagen 1A2 (COL1A2)-whereas DI is associated with DSPP gene mutation. ${ }^{68,69} \mathrm{An}$ early diagnosis of DI is important in preventing further attrition of teeth as well as reduction in the vertical dimension of occlusion, so as to preserve function, aesthetics, and normal growth.

\section{Genetic Defects Manifested Late in Tooth Development}

\section{Taurodontism}

Taurodontism (OMIM \#272700) refers to "Tauro" (Bull) and "dont" (tooth) is a developmental anomaly characterized by a large pulp chamber of a multirooted tooth with an apical displacement of pulp floor and bifurcation of the roots. ${ }^{70}$ It may occur as an isolated trait or more often a part of a syndrome. It affects more often permanent dentition than primary teeth. The reported prevalence is 0.5 to $46 \%$ and it can occur unilaterally or bilaterally. Usually, molars are affected with increased severity being reported in the second and third molars. ${ }^{71}$ Both environmental and genetic factors are responsible for taurodontism. The exact etiology of taurodontism is still unknown, but a delay or failure of Herwig's epithelial root sheath to invaginate into mesenchyme reflects in the apical displacement of root furcation, thus resulting in the development of taurodontism. $^{72}$

There are several syndromes where taurodontism has been identified like osteogenesis imperfecta, Torg-Winchester syndrome, TDO, cleft lip, and palate. ${ }^{73}$ TDO syndrome is associated with DLX3 gene mutations, which are also associated with amelogenesis imperfecta hypoplastic hypomaturation with taurodontism. ${ }^{74}$ Taurodontism is also seen in Torg-Winchester syndrome, which is associated with matrix metalloproteinase 2 (MMP2) genetic mutations. ${ }^{75}$

\section{Conclusion}

Tooth developmental anomalies involving size, shape, number, quality, or quantity of tooth structure involve alterations in dentitions, which result in dental disharmony causing functional and aesthetic problems. Multiple genes are known to be engaged in normal tooth development, and the complex interactions between genetic, epigenetic, and environmental factors result in the development of dental anomalies. The identification of the genetic causes of these anomalies enables clinicians and researchers for a better understanding of molecular pathogenesis. In the near future, it helps provide a more accurate diagnosis and biologicalbased treatment for these dental anomalies.

Conflict of Interest

None declared.

\section{References}

1 Galluccio G, Castellano M, La Monaca C. Genetic basis of nonsyndromic anomalies of human tooth number. Arch Oral Biol 2012;57(07):918-930

2 Brook AH. Multilevel complex interactions between genetic, epigenetic and environmental factors in the aetiology of anomalies of dental development. Arch Oral Biol 2009;54(Suppl 1): S3-S17

3 de La Dure-Molla M, Fournier BP, Manzanares MC, et al; International Group of Dental Nomenclature. Elements of morphology: standard terminology for the teeth and classifying genetic dental disorders. Am J Med Genet A 2019;179(10):1913-1981

4 Cakan DG, Ulkur F, Taner T. The genetic basis of dental anomalies and its relation to orthodontics. Eur J Dent 2013;7(Suppl 1): S143-S147

5 Vastardis H. The genetics of human tooth agenesis: new discoveries for understanding dental anomalies. Am J Orthod Dentofacial Orthop 2000;117(06):650-656

6 Klein OD, Oberoi S, Huysseune A, Hovorakova M, Peterka M, Peterkova R. Developmental disorders of the dentition: an update. Am J Med Genet C Semin Med Genet 2013;163C(04): 318-332 
7 Thesleff I. Epithelial-mesenchymal signalling regulating tooth morphogenesis. J Cell Sci 2003;116(Pt 9):1647-1648

8 Bailleul-Forestier I, Molla M, Verloes A, Berdal A. The genetic basis of inherited anomalies of the teeth. Part 1: clinical and molecular aspects of non-syndromic dental disorders. Eur J Med Genet 2008;51(04):273-291

9 Thesleff I. The genetic basis of tooth development and dental defects. Am J Med Genet A 2006;140(23):2530-2535

10 Thesleff I. The genetic basis of normal and abnormal craniofacial development. Acta Odontol Scand 1998;56(06):321-325

11 Diekwisch TG. Pathways and fate of migratory cells during late tooth organogenesis. Connect Tissue Res 2002;43(2-3):245-256

12 Sharpe PT. Neural crest and tooth morphogenesis. Adv Dent Res 2001;15:4-7

13 Lisi S, Peterková R, Peterka M, Vonesch JL, Ruch JV, Lesot H. Tooth morphogenesis and pattern of odontoblast differentiation. Connect Tissue Res 2003;44(Suppl 1):167-170

14 Matalova E, Fleischmannova J, Sharpe PT, Tucker AS. Tooth agenesis: from molecular genetics to molecular dentistry. J Dent Res 2008;87(07):617-623

15 Kavitha B, Priyadharshini V, Sivapathasundharam B, Saraswathi TR. Role of genes in oro-dental diseases. Indian J Dent Res 2010;21 (02):270-274

16 Cobourne MT. Familial human hypodontia: is it all in the genes? Br Dent J 2007;203(04):203-208

17 Sharpe PT. Homeobox genes and orofacial development. Connect Tissue Res 1995;32(1-4):17-25

18 Thesleff I. Homeobox genes and growth factors in regulation of craniofacial and tooth morphogenesis. Acta Odontol Scand 1995; 53(03):129-134

19 Neubüser A, Peters H, Balling R, Martin GR. Antagonistic interactions between FGF and BMP signaling pathways: a mechanism for positioning the sites of tooth formation. Cell 1997;90(02):247-255

20 Mostowska A, Biedziak B, Zadurska M, Dunin-Wilczyńska I, Lianeri M, Jagodziński PP. Nucleotide variants of genes encoding components of the Wnt signalling pathway and the risk of nonsyndromic tooth agenesis. Clin Genet 2013;84(05):429-440

21 James MJ, Järvinen E, Wang XP, Thesleff I. Different roles of Runx2 during early neural crest-derived bone and tooth development. J Bone Miner Res 2006;21(07):1034-1044

22 Merametdjian L, Prud'Homme T, Le Caignec C, Isidor B, LopezCazaux S. Oro-dental phenotype in patients with RUNX2 duplication. Eur J Med Genet 2019;62(02):85-89

23 De Coster PJ, Marks LA, Martens LC, Huysseune A. Dental agenesis: genetic and clinical perspectives. J Oral Pathol Med 2009;38(01): 1-17

24 Rakhshan V. Congenitally missing teeth (hypodontia): a review of the literature concerning the etiology, prevalence, risk factors, patterns and treatment. Dent Res J (Isfahan) 2015;12(01):1-13

25 Soni HK, Joshi M, Desai H, Vasavada M. An orthopantomographic study of prevalence of hypodontia and hyperdontia in permanent dentition in Vadodara, Gujarat. Indian J Dent Res 2018;29(04): 529-533

26 Jurek A, Gozdowski D, Zadurska M. Agenesis of permanent teeth: a report based on cases from clinical practice. Forum Ortod 2019; $15: 263-271$

27 Gerits A, Nieminen P, De Muynck S, Carels C. Exclusion of coding region mutations in MSX1, PAX9 and AXIN2 in eight patients with severe oligodontia phenotype. Orthod Craniofac Res 2006;9(03): 129-136

28 Vieira AR, Meira R, Modesto A, Murray JC. MSX1, PAX9, and TGFA contribute to tooth agenesis in humans. J Dent Res 2004;83(09): 723-727

29 Lidral AC, Reising BC. The role of MSX1 in human tooth agenesis. J Dent Res 2002;81(04):274-278

30 Vastardis H, Karimbux N, Guthua SW, Seidman JG, Seidman CE. A human MSX1 homeodomain missense mutation causes selective tooth agenesis. Nat Genet 1996;13(04):417-421
31 Kim JW, Simmer JP, Lin BP, Hu JC. Novel MSX1 frameshift causes autosomal-dominant oligodontia. J Dent Res 2006;85(03): 267-271

32 Stockton DW, Das P, Goldenberg M, D'Souza RN, Patel PI. Mutation of PAX9 is associated with oligodontia. Nat Genet 2000;24(01): $18-19$

33 Kapadia H, Mues G, D'Souza R. Genes affecting tooth morphogenesis. Orthod Craniofac Res 2007;10(03):105-113

34 Peters H, Neubüser A, Balling R. Pax genes and organogenesis: Pax9 meets tooth development. Eur J Oral Sci 1998;106 (Suppl 1):38-43

35 Brook AH, Elcock C, Aggarwal M, et al. Tooth dimensions in hypodontia with a known PAX9 mutation. Arch Oral Biol 2009; 54(Suppl 1):S57-S62

36 Nieminen P, Arte S, Tanner D, et al. Identification of a nonsense mutation in the PAX9 gene in molar oligodontia. Eur J Hum Genet 2001;9(10):743-746

37 Klein ML, Nieminen P, Lammi L, Niebuhr E, Kreiborg S. Novel mutation of the initiation codon of PAX9 causes oligodontia. J Dent Res 2005;84(01):43-47

38 Mostowska A, Kobielak A, Trzeciak WH. Molecular basis of nonsyndromic tooth agenesis: mutations of MSX1 and PAX9 reflect their role in patterning human dentition. Eur J Oral Sci 2003;111 (05):365-370

39 Lammi L, Arte S, Somer M, et al. Mutations in AXIN2 cause familial tooth agenesis and predispose to colorectal cancer. Am J Hum Genet 2004;74(05):1043-1050

40 Polder BJ, Van't Hof MA, Van der Linden FP, Kuijpers-Jagtman AM. A meta-analysis of the prevalence of dental agenesis of permanent teeth. Community Dent Oral Epidemiol 2004;32(03): 217-226

41 Kantaputra P, Sripathomsawat W. WNT10A and isolated hypodontia. Am J Med Genet A 2011;155A(05):1119-1122

42 Song $S$, Han D, Qu H, et al. EDA gene mutations underlie nonsyndromic oligodontia. J Dent Res 2009;88(02):126-131

43 Khabour OF, Mesmar FS, Al-Tamimi F, Al-Batayneh OB, Owais AI Missense mutation of the EDA gene in a Jordanian family with Xlinked hypohidrotic ectodermal dysplasia: phenotypic appearance and speech problems. Genet Mol Res 2010;9(02):941-948

44 Tao R, Jin B, Guo SZ, et al. A novel missense mutation of the EDA gene in a Mongolian family with congenital hypodontia. J Hum Genet 2006;51(05):498-502

45 Han D, Gong Y, Wu H, et al. Novel EDA mutation resulting in Xlinked non-syndromic hypodontia and the pattern of EDA-associated isolated tooth agenesis. Eur J Med Genet 2008;51(06): 536-546

46 Subasioglu A, Savas S, Kucukyilmaz E, Kesim S, Yagci A, Dundar M. Genetic background of supernumerary teeth. Eur J Dent 2015;9 (01):153-158

47 Wang XP, Fan J. Molecular genetics of supernumerary tooth formation. Genesis 2011;49(04):261-277

48 Anthonappa RP, King NM, Rabie AB. Aetiology of supernumerary teeth: a literature review. Eur Arch Paediatr Dent 2013;14(05): 279-288

49 Solares R, Romero MI. Supernumerary premolars: a literature review. Pediatr Dent 2004;26(05):450-458

50 Küchler EC, Costa AG, Costa MdeC, Vieira AR, Granjeiro JM. Supernumerary teeth vary depending on gender. Braz Oral Res 2011;25(01):76-79

51 Cohen MM Jr. Biology of RUNX2 and cleidocranial dysplasia. J Craniofac Surg 2013;24(01):130-133

52 Inchingolo F, Tatullo M, Abenavoli FM, et al. Non-syndromic multiple supernumerary teeth in a family unit with a normal karyotype: case report. Int J Med Sci 2010;7(06):378-384

53 Bäckman B, Holmgren G. Amelogenesis imperfecta: a genetic study. Hum Hered 1988;38(04):189-206

54 Nusier M, Yassin O, Hart TC, Samimi A, Wright JT. Phenotypic diversity and revision of the nomenclature for autosomal 
recessive amelogenesis imperfecta. Oral Surg Oral Med Oral Pathol Oral Radiol Endod 2004;97(02):220-230

55 Greene SR, Yuan ZA, Wright JT, et al. A new frameshift mutation encoding a truncated amelogenin leads to X-linked amelogenesis imperfecta. Arch Oral Biol 2002;47(03):211-217

56 Dong J, Gu TT, Simmons D, MacDougall M. Enamelin maps to human chromosome 4q21 within the autosomal dominant amelogenesis imperfecta locus. Eur J Oral Sci 2000;108(05):353-358

57 Ozdemir D, Hart PS, Firatli E, Aren G, Ryu OH, Hart TC. Phenotype of ENAM mutations is dosage-dependent. J Dent Res 2005;84(11): 1036-1041

58 Kim JW, Simmer JP, Hart TC, et al. MMP-20 mutation in autosomal recessive pigmented hypomaturation amelogenesis imperfecta. J Med Genet 2005;42(03):271-275

59 Hart PS, Hart TC, Michalec MD, et al. Mutation in kallikrein 4 causes autosomal recessive hypomaturation amelogenesis imperfecta. J Med Genet 2004;41(07):545-549

60 Dong J, Amor D, Aldred MJ, Gu T, Escamilla M, MacDougall M. DLX3 mutation associated with autosomal dominant amelogenesis imperfecta with taurodontism. Am J Med Genet A 2005;133A(02):138-141

61 Wright JT, Kula K, Hall K, Simmons JH, Hart TC. Analysis of the tricho-dentoosseous syndrome genotype and phenotype. Am J Med Genet 1997;72(02):197-204

$62 \mathrm{Hu}$ JC, Simmer JP. Developmental biology and genetics of dental malformations. Orthod Craniofac Res 2007;10(02):45-52

63 Hart PS, Hart TC. Disorders of human dentin. Cells Tissues Organs 2007;186(01):70-77

64 MacDougall M, Jeffords LG, Gu TT, et al. Genetic linkage of the dentinogenesis imperfecta type III locus to chromosome 4q. J Dent Res 1999;78(06):1277-1282
65 Barron MJ, McDonnell ST, Mackie I, Dixon MJ. Hereditary dentine disorders: dentinogenesis imperfecta and dentine dysplasia. Orphanet J Rare Dis 2008;3:31

66 Lee SK, Lee KE, Jeon D, et al. A novel mutation in the DSPP gene associated with dentinogenesis imperfecta type II. J Dent Res 2009;88(01):51-55

67 Surendra P, Shah R, Roshan NM, Reddy VVS. Dentinogenesis imperfecta: a family which was affected for over three generations. J Clin Diagn Res 2013;7(08):1808-1811

68 Zhang X, Zhao J, Li C, et al. DSPP mutation in dentinogenesis imperfecta Shields type II. Nat Genet 2001;27(02):151-152

69 Rios D, Vieira AL, Tenuta LM, Machado MA. Osteogenesis imperfecta and dentinogenesis imperfecta: associated disorders. Quintessence Int 2005;36(09):695-701

70 MacDonald D. Taurodontism. Oral Radiol 2020;36(02):129-132

71 Gomes RR, Habckost CD, Junqueira LG, et al. Taurodontism in Brazilian patients with tooth agenesis and first and seconddegree relatives: a case-control study. Arch Oral Biol 2012;57 (08):1062-1069

72 Jayashankara C, Shivanna AK, Sridhara K, Kumar PS. Taurodontism: a dental rarity. J Oral Maxillofac Pathol 2013;17(03):478

73 Chetty M, Roomaney IA, Beighton P. Taurodontism in dental genetics. BDJ Open 2021;7(01):25

74 Whitehouse LLE, Smith CEL, Poulter JA, et al. Novel DLX3 variants in amelogenesis imperfecta with attenuated tricho-dento-osseous syndrome. Oral Dis 2019;25(01):182-191

75 Andersson EM, Axelsson S, Gjølstad LF, Storhaug K. Taurodontism: a minor diagnostic criterion in Laurence-Moon/Bardet-Biedl syndromes. Acta Odontol Scand 2013;71(06):1671-1674 